\title{
Does Diabetes Mellitus Influence Standardized Uptake Values of Fluorodeoxyglucose Positron Emission Tomography in Colorectal Cancer?
}

\author{
Da Yeon $\mathrm{Oh}^{1,2}$, Ji Won Kim ${ }^{1,2}$, Seong-Joon $\mathrm{Koh}^{1,2}$, Mingoo Kim ${ }^{1,2}$, Ji Hoon Park ${ }^{1,2}$, Su Yeon Cho ${ }^{1,2}$, \\ Byeong Gwan Kim ${ }^{1,2}$, Kook Lae Lee ${ }^{1,2}$, Jong Pil Im ${ }^{1}$ \\ Department of Internal Medicine, Seoul National University College of Medicinel', Seoul National University Boramae Hospital', Seoul, Korea
}

Background/Aims: Hyperglycemia is associated with decreased $2{ }^{-18}[$ F]fluoro-2-deoxy-D-glucose (FDG) uptake by tumors assessed by positron emission tomography (PET). In this retrospective study we investigated a comparison of standardized uptake values (SUVs) in patients with primary colorectal cancers who either had diabetes mellitus (DM) or were otherwise healthy. Methods: The medical records of 397 patients who were diagnosed with colorectal cancer and underwent PETCT between January 2006 and December 2012 were analyzed. Eighty patients with DM and 317 patients without DM were included. Clinical characteristics were reviewed and maximal standardized uptake values $\left(\mathrm{SUV}_{\max }\right)$ were calculated in the primary colorectal lesions. Results: There was no significant difference between tumor $\mathrm{SUV}_{\max }$ in DM patients (10.60 \pm 5.78$)$ and those without DM (10.92 \pm 5.44$)$. In addition, no significant difference was detected between tumor $\mathrm{SUV}_{\max }$ in DM patients with glycated hemoglobin (HbAlc) levels $<8 \%(10.34 \pm 5.17)$ and those with HbAlc levels $\geq 8 \%(10.61 \pm 7.27)$. The maximum size of the primary colorectal tumor was associated with $\mathrm{SUV}_{\max }$ in a linear regression analysis. Conclusion: The results of this study showed that DM did not influence FDG uptake values in colorectal cancer patients regardless of glucose levels. (Intest Res 2014;12:146-152)

Key Words: Diabetes mellitus; Positron emission tomography; Colorectal neoplasms

\section{INTRODUCTION}

The incidence of colorectal cancer, the fourth and second leading causes of death in men (15.4\%) and women (12.1\%), respectively, ${ }^{1}$ has been gradually increasing in Korea since 2000. Additionally, the prevalence of diabetes mellitus (DM) has increased rapidly in the last three decades in Korea and is forecasted to increase from $8.6 \%$ in 2007 to $10.8 \%$ in $2015 .^{2}$ As the prevalence of DM has increased, the risk of colon

Received September 22, 2013. Revised January 24, 2014. Accepted January 28, 2014.

Correspondence to Ji Won Kim, Department of Internal Medicine, Seoul National University Boramae Hospital, 20 Boramae-ro 5-gil, Dongjak-gu, Seoul 156-707, Korea. Tel: +82-2-870-2221, Fax: +82-2-870-3863, E-mail: giwkim@hanmail.net

Financial support: None. Conflict of interest: None. cancer, pancreatic cancer, bladder cancer, breast cancer, and others has been increasing as well. ${ }^{3,4}$ Contrast-enhanced abdomino-pelvic CT and PET-CT are used in preoperative local staging evaluations and in diagnosing metastasis. A PETCT scan is performed after injecting a non-metabolizable glucose sugar analogue, such as ${ }^{18}[\mathrm{~F}]$-Fluorodeoxyglucose (FDG), ${ }^{1}$ that remains in cells as an intermediate product. The degree of ${ }^{18}[\mathrm{~F}]$-FDG accumulation in cells with active metabolism is referred to as the standardized uptake value. ${ }^{5}$ Although FDG uptake in the bowel is often influenced by the amount of intracellular mucus, cell size, peristaltic movement, white blood cell count, and others, ${ }^{6}$ maximal standardized uptake values $\left(\mathrm{SUV}_{\max }\right)$ are elevated by an increase in the FDG accumulation in cancer cells with active metabolism. When blood glucose levels are high, elevated glucose levels can prevent FDG uptake in malignant tumor

๑ Copyright 2014. Korean Association for the Study of Intestinal Diseases. All rights reserved.

This is an Open Access article distributed under the terms of the Creative Commons Attribution Non-Commercial License (http://creativecommons.org/licenses/by-nc/3.0)

which permits unrestricted non-commercial use, distribution, and reproduction in any medium, provided the original work is properly cited. 
cells due to a competitive reaction. This may lead to decreased $\mathrm{SUV}_{\text {max }}$ values, as FDG uptake is relatively lowered in malignant neoplasms. ${ }^{7,8}$ However, previous studies on the association between blood glucose levels and $\mathrm{SUV}_{\max }$ in PET-CT have mainly been focused on patients without DM. This study aimed to investigate the effect of DM in patients with colorectal cancer on $\mathrm{SUV}_{\text {max }}$ as well as the difference in $\mathrm{SUV}_{\text {max }}$ based on the degree of blood glucose control.

\section{METHODS}

\section{Subjects}

This study included 397 patients diagnosed with colorectal cancer through histopathological examination in the SMG-SNU Boramae Medical Center from January 2006 to December 2012 who also underwent FDG PET-CT scans. Data were collected from patients through reviewing clinical and radiologic records and pathologic examination and included age, sex, BMI, presence of DM, blood glucose levels, glycated hemoglobin (HbAlc) levels, postoperative lesion sizes, histological findings and stages, and others. We excluded patients with severe infections and inflammatory diseases that could affect test results, those with tumors in other organs, and those with unknown $\mathrm{SUV}_{\text {max }}$ values due to lack of FDG PET-CT scan data. In addition, we also excluded DM patients without confirmed blood glucose examinations and those without HbAlc levels collected in the two months prior to the PET scan. Colorectal cancer was diagnosed based on pathologic results and Tumour, Node, Metastases staging was based on the results of contrast-enhanced abdominopelvic CT, PET scan, colonoscopy, and pathologic results. This study received approval from the Institutional Review Board of the SMG-SNU Boramae Medical Center.

\section{PET-CT Scan}

Patients underwent FDG PET-CT scan after 8-hours of fasting. Blood glucose levels were measured prior to scanning, and patients without and with DM having levels $<120$ $\mathrm{mg} / \mathrm{dL}$ and $<180 \mathrm{mg} / \mathrm{dL}$, respectively, received PET-CT. Patients drank sufficient water before the exam and then received $5.18 \mathrm{MBq}$ of ${ }^{18}[\mathrm{~F}]$-FDG per $\mathrm{kg}$ of body weight intravenously. PET scan images were obtained after $60 \mathrm{~min}$ using a GEMINI TF-64 scanner (Phillips Medical System, Cleveland, OH, USA). CT scanning was conducted from the basal skull to the femoral region, and attenuation correction was performed in CT images. After CT scanning, PET scans were conducted for 2.5 min per frame according to standard protocols. Sixty minutes have passed after intravenous injection of FDG, the image taking was performed. If the focal FDG uptake was seen in the captured image, and then further delayed images were taken after 4 hours later. Two nuclear medicine specialists evaluated uptake regions and $\mathrm{SUV}_{\max }$ by interpreting PET scan images. $S_{U} V_{\max }$, the maximum amount of FDG accumulation in tumors depending on the dose of ${ }^{18}[\mathrm{~F}]$-FDG injected with FDG-PET activity, was calculated using the percentage of the average rate of whole body uptake and the uptake rate for lesions.

\section{Pathological Findings}

Surgical resection was performed in 397 patients diagnosed with colorectal cancer and confirmed with endoscopic biopsy. Tumor size and the degree of infiltration were measured through pathologic examination after resection. The diameter of lesions was measured as lesion size after formalin fixation. The location of lesions was categorized into the proximal portion from the cecum to the transverse colon, the distal portion from the splenic flexure to the sigmoid colon, and the rectum area below the sigmoid colon. Anastomosis was defined in patients with a history of intestinal surgery. Lesions were classified into polypoid, ulceroinfiltrative, and ulcerofungating based on gross type, and neoplasms were generally categorized into well differentiated, moderately differentiated, and poorly differentiated carcinoma. In addition, lymph node metastasis, perineural infiltration, lymphatic invasion, and vascular invasion were examined in surgically resected tissues.

\section{FDG-PET Findings according to the Level of Blood Glucose Control}

We examined differences in patients with DM and colorectal cancer to identify the effects of HbAlc levels on $\mathrm{SUV}_{\max }$ by dividing them into two groups, well-controlled and poorly controlled. By reviewing HbAlc levels measured in the two months prior to the PET scan, $\mathrm{SUV}_{\max }$ values could be compared between patients with DM and HbAlc levels $<8 \%$ and those with HbAlc levels $\geq 8 \%$.

\section{Statistical Analysis}

Statistical analyses were performed using the SPSS version 20.0 for Windows (SPSS Inc., Chicago, IL, USA). $P$-values of less than 0.05 were considered statistically significant. 
$T$-tests and one-way ANOVAs were used to analyze continuous variables, and $\mathrm{X}^{2}$-tests or Fisher's exact tests were performed to analyze categorical variables. Linear regression was conducted to examine the association between $\mathrm{SUV}_{\max }$ and colorectal cancer-related factors. Multiple linear regression was performed on factors demonstrating $P$-values of less than 0.25 in a simple linear regression analysis.

\section{RESULTS}

\section{Characteristics of Patients by the Presence of DM}

Among 397 patients, 268 (67.5\%) were men and 129 (32.5\%) were women. Of these patients with colorectal cancer, 80 (20.2\%) were patients with DM and 317 (79.8\%) did not have DM. Of the 80 patients with DM, 57 (71.3\%) were undergoing therapy with oral hypoglycemic agents (OHA), 10 (12.5\%) were receiving insulin, 3 (3.8\%) were undergoing combined insulin-OHA therapy, and 10 (12.5\%) were applying lifestyle modification therapies without medication. The mean HbAlc level in patients with DM was $8.06 \pm 2.15 \%$ and the mean duration of DM was $8.25 \pm 6.81$ years.

The mean age of patients with DM was $66.88 \pm 9.79$ years, significantly older than that of patients without DM $(64.24 \pm 11.65$ years; $P=0.040$ ), however no difference was found in the BMIs of patients in the two groups. Blood glucose levels were significantly different between patients with and without DM $(154.71 \pm 69.38 \mathrm{mg} / \mathrm{dL}$ vs. $103.17 \pm 18.50 \mathrm{mg} /$ $\mathrm{dL} ; P<0.001)$.

According to the results of the pathologic examinations, adenocarcinoma was the most common type of colorectal cancer in both groups (DM vs. Non-DM: 97.5\% vs. 93.4\%). Regarding the location, colorectal cancers occurred most commonly in the rectum in both groups (DM vs. Non-DM: $41.2 \%$ vs. $37.5 \%$ ). Analysis of gross type indicated that ulceroinfiltrative and ulcerofungating lesions accounted for $45.0 \%$ and $43.8 \%$, respectively, of all patients with DM, and $46.4 \%$ and $41.3 \%$, respectively, of all patients without DM, showing no difference between the groups. According to the American Joint Committee on Cancer staging system, stages III and IV colorectal cancer accounted for $32.5 \%$ and $33.8 \%$, respectively, of all patients with DM, and $33.1 \%$ and $26.2 \%$, respectively, of all patients without DM, showing no difference between the groups (Table 1).

\section{Characteristics of FDG Uptake in the Presence of DM}

When the $\mathrm{SUV}_{\text {max }}$ values of colorectal cancer were com-
Table 1. Baseline Characteristics of Patients with and without Diabetes Mellitus

\begin{tabular}{|c|c|c|c|}
\hline & $\begin{array}{c}\text { DM } \\
(n=80)\end{array}$ & $\begin{array}{l}\text { Non-DM } \\
(n=317)\end{array}$ & $P$-value \\
\hline Sex & & & 0.109 \\
\hline Male & $60(75.0)$ & $208(65.6)$ & \\
\hline Age (yr) & $66.88 \pm 9.79$ & $64.24 \pm 11.65$ & 0.040 \\
\hline BMI & $23.03 \pm 3.19$ & $22.48 \pm 3.19$ & 0.175 \\
\hline$S U V_{\max }$ & $10.60 \pm 5.78$ & $10.92 \pm 5.44$ & 0.642 \\
\hline $\mathrm{HbA1c}(\%)$ & $8.06 \pm 2.15$ & & \\
\hline DM duration (yr) & $8.25 \pm 6.81$ & & \\
\hline \multicolumn{4}{|l|}{ Treatment } \\
\hline $\mathrm{OHA}$ & 57 (71.3) & & \\
\hline Insulin & $10(12.5)$ & & \\
\hline $\mathrm{OHA}+$ Insulin & $3(3.8)$ & & \\
\hline Observation & $10(12.5)$ & & \\
\hline Maximum size of lesion (mm) & $48.90 \pm 25.02$ & $50.08 \pm 28.71$ & 0.737 \\
\hline Glucose (mg/dL) & $154.71 \pm 69.38$ & $103.17 \pm 18.50$ & $<0.001$ \\
\hline Pathologic type & & & 0.589 \\
\hline Adenocarcinoma & 78 (97.5) & 296 (93.4) & \\
\hline Signet ring cell & $0(0.0)$ & $4(1.3)$ & \\
\hline Mucinous carcinoma & $2(2.5)$ & $9(2.8)$ & \\
\hline Others & $0(0.0)$ & $8(2.5)$ & \\
\hline Location & & & 0.704 \\
\hline Proximal & 19 (23.8) & 95 (30.0) & \\
\hline Distal & $26(32.5)$ & $97(30.6)$ & \\
\hline Rectum & 33 (41.2) & 119 (37.5) & \\
\hline Anastomosis & $2(2.5)$ & $6(1.9)$ & \\
\hline AJCC stage & & & 0.729 \\
\hline 0 & $1(1.2)$ & $6(1.9)$ & \\
\hline 1 & $6(7.5)$ & $33(10.4)$ & \\
\hline$\|$ & $20(25.0)$ & $90(28.4)$ & \\
\hline III & $26(32.5)$ & 105 (33.1) & \\
\hline N & 27 (33.8) & 83 (26.2) & \\
\hline Gross type & & & 0.916 \\
\hline Polypoid & $9(11.2)$ & 39 (12.3) & \\
\hline Ulceroinfiltrative & $36(45.0)$ & $147(46.4)$ & \\
\hline Ulcerofungating & $35(43.8 \%)$ & $131(41.3 \%)$ & \\
\hline \multicolumn{4}{|c|}{$\begin{array}{l}\text { Values are presented as mean } \pm \text { SD or } n(\%) \text {. } \\
\text { SUV }_{\max } \text { maximum standardized uptake values; HbA1c, glycated } \\
\text { hemoglobin; DM, diabetes mellitus; } \mathrm{OHA} \text {, oral hypoglycemic agent; } \\
\text { AAJC, American Joint Committee on Cancer. }\end{array}$} \\
\hline
\end{tabular}


pared according to the presence of DM, the $\mathrm{SUV}_{\text {max }}$ was $10.60 \pm 5.78$ in patients with DM and $10.92 \pm 5.44$ in patients without DM, exhibiting no difference between the groups $(P=0.642$; Fig. 1$)$.

Among the 80 total patients with DM, differences in $\mathrm{SUV}_{\max }$

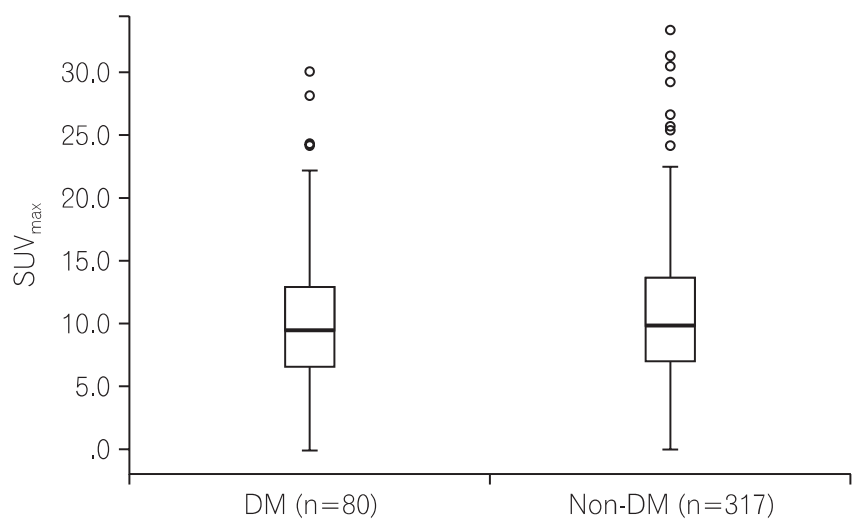

Fig. 1. Comparison of maximal standardized uptake values $\left(S U V_{\max }\right)$ in colorectal cancer patients with or without diabetes mellitus (DM) $(P=0.642)$.

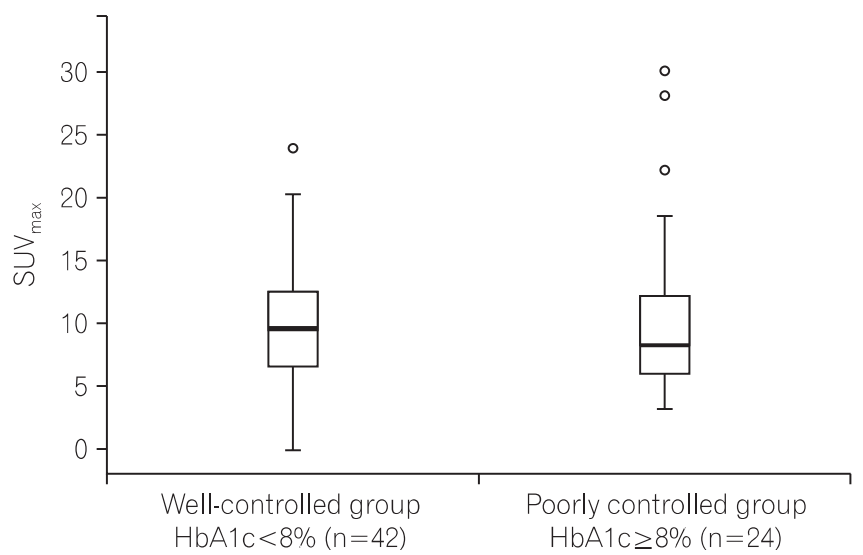

Fig. 2. Comparison of maximal standardized uptake values $\left(S U V_{\max }\right)$ in colorectal cancer patients with diabetes mellitus (DM) according to control of glucose $(P=0.860)$. HbA1c, glycated hemoglobin. were examined according to glucose levels in 66 patients who had available HbAlc data. Patients with DM were classified into a well-controlled group ( $\mathrm{n}=42$ ) with HbAlc levels $<8 \%$ and a poorly controlled group ( $\mathrm{n}=24$ ) with HbAlc levels $\geq 8 \%$. $\mathrm{SUV}_{\text {max }}$ values were $10.34 \pm 5.17$ in the well-controlled group and $10.61 \pm 7.27$ in the poorly controlled group, showing no significant difference between the groups ( $P=0.860$; Fig. 2$)$. Moreover, no differences were found in age, sex, BMI, lesion size, or the duration of DM between two groups (Table 2).

To identify a correlation between $\mathrm{SUV}_{\text {max }}$ and blood glucose levels, scattergrams of blood glucose levels and $\mathrm{SUV}_{\text {max }}$ were compared. As a result, no correlation was found between blood glucose levels and $\mathrm{SUV}_{\max }$ (correlation coefficient $-0.051[P=0.657]$; Fig. 3 ).

When $\mathrm{SUV}_{\text {max }}$ values were compared according to treatment methods used by patients with DM, a trend towards higher $\mathrm{SUV}_{\text {max }}$ values was observed in the group using combined insulin-OHA therapy as compared to the values from groups of patients using only an OHA, only insulin, or only being observed. However, no significant difference was de-

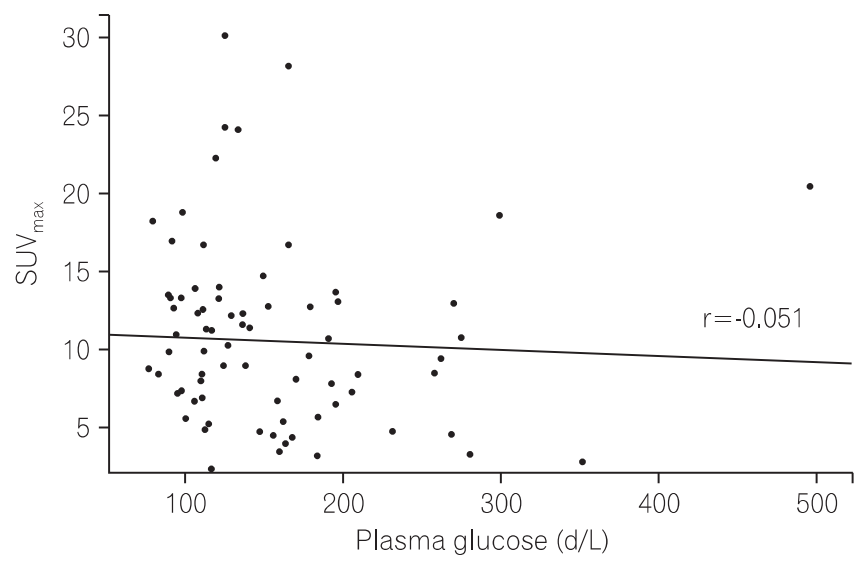

Fig. 3. Distribution between maximal standardized uptake values (SU$V_{\text {max }}$ ) and glucose in diabetes mellitus (DM) patients. The correlation coefficient(r) was -0.051 .

Table 2. Characteristics according to Level of Glucose Control in Patients with Diabetes Mellitus

\begin{tabular}{|c|c|c|c|}
\hline & $\begin{array}{l}\text { Well-controlled group } \\
\mathrm{HbA} 1 \mathrm{c}<8 \%(n=42)\end{array}$ & $\begin{array}{l}\text { Poorly controlled group } \\
\text { HbA1c } \geq 8 \%(n=24)\end{array}$ & $P$-value \\
\hline $\mathrm{SUV}_{\max }$ & $10.34 \pm 5.17$ & $10.61 \pm 7.27$ & 0.860 \\
\hline DM duration (yr) & $8.06 \pm 7.68$ & $8.11 \pm 6.17$ & 0.982 \\
\hline Maximum size of lesion (mm) & $49.21 \pm 30.29$ & $47.83 \pm 17.17$ & 0.814 \\
\hline Glucose (mg/dL) & $151.48 \pm 77.79$ & $172.00 \pm 62.64$ & 0.274 \\
\hline
\end{tabular}

Values are presented as mean \pm SD.

HbA1c, glycated hemoglobin; SUV maxı $_{1}$ maximum standardized uptake values; DM, diabetes mellitus. 


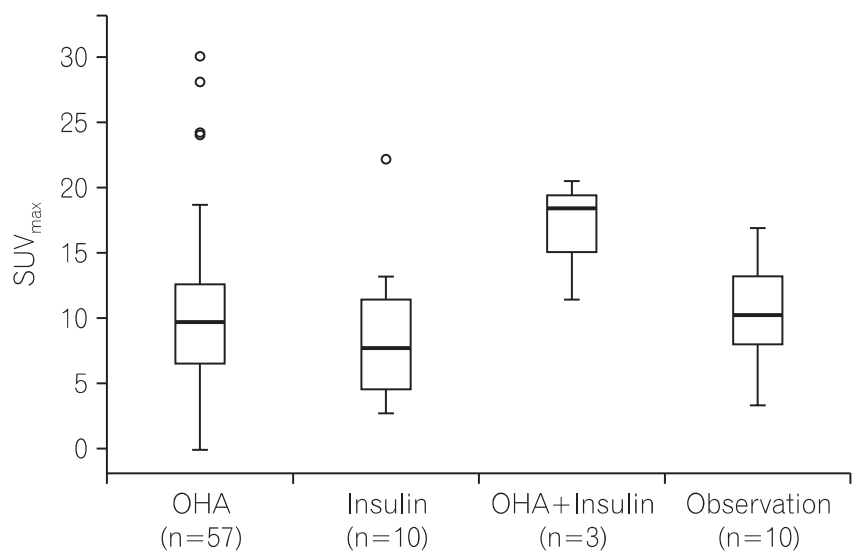

Fig. 4. Difference of maximal standardized uptake values $\left(S U V_{\text {max }}\right)$ in diabetes mellitus (DM) patients $(n=80)$ according to treatment $(P=0.239)$. $\mathrm{OHA}$, oral hypoglycemic agent.

tected between these groups $(P=0.239$; Fig. 4$)$.

\section{Factors Affecting FDG Uptake}

In the analysis of factors influencing $\mathrm{SUV}_{\text {max }}$ in patients with DM, the maximum size of the colorectal lesion was identified as the only factor that affected $\mathrm{SUV}_{\text {max }}$. There was no correlation between $\mathrm{SUV}_{\max }$ values and BMI, the duration of DM, blood glucose levels, HbAlc levels, gross types, or Tumour, Node, Metastases staging (Table 3).

\section{DISCUSSION}

FDG uptake is elevated in malignant tumor tissues, as these tissues use energy mainly from glucose metabolic processes for survival. When blood glucose levels are high, elevated glucose levels can prevent FDG uptake in malignant tumor tissues due to a competitive reaction. This process is known to lower both the resolution of PET-CT scans and diagnostic sensitivity. ${ }^{7}$ Only a few studies have investigated changes in FDG uptake in tumors of patients with DM and chronically elevated glucose levels. ${ }^{9}$ The current study is the first to compare the differences in tumor $S_{U} V_{\text {max }}$ values during PET-CT according to the presence of DM in patients with colorectal cancer. No significant difference was found in $\mathrm{SUV}_{\max }$ values between patients with and without DM. Only tumor size was identified as a factor that could influence $\mathrm{SUV}_{\text {max }}$.

These results were comparable to those of a previous study that compared $\mathrm{SUV}_{\text {max }}$ values between patients with and without DM with esophageal cancer. Haley et al. ${ }^{10}$ compared pre-treatment $S U V_{\max }$ values in 18 esophageal cancer patients with DM and 45 esophageal cancer patients with-
Table 3. Predictive Factors Associated with Maximum Standardized Uptake Values

\begin{tabular}{|c|c|c|c|}
\hline \multirow{2}{*}{ Variable } & \multicolumn{3}{|c|}{ Simple linear regression } \\
\hline & Estimate & F-statistic & $P$-value \\
\hline \multicolumn{4}{|l|}{ Sex } \\
\hline Male vs. Female & 0.544 & 0.131 & 0.719 \\
\hline Age & -0.027 & 0.155 & 0.695 \\
\hline BMI & 0.429 & 4.524 & 0.037 \\
\hline DM duration & -0.023 & 0.057 & 0.812 \\
\hline Maximum size of lesion & 0.107 & 20.899 & $<0.001$ \\
\hline Glucose & -0.004 & 0.199 & 0.657 \\
\hline $\mathrm{HbA1c}$ & 0.408 & 1.396 & 0.242 \\
\hline \multicolumn{4}{|l|}{ Pathologic type } \\
\hline Mucinous ca. vs. Adenoca. & -1.074 & 0.066 & 0.797 \\
\hline Location & & 0.153 & 0.928 \\
\hline Distal vs. Proximal & 0.162 & 0.008 & 0.928 \\
\hline Rectum vs. Proximal & -0.429 & 0.062 & 0.804 \\
\hline Anastomosis vs. Proximal & -2.434 & 0.308 & 0.580 \\
\hline \multicolumn{4}{|l|}{ T stage } \\
\hline T3, T4 vs. Tis, T1, T2 & 3.900 & 2.973 & 0.089 \\
\hline \multicolumn{4}{|l|}{ N stage } \\
\hline N2 vs. N0, N1 & 1.123 & 0.655 & 0.421 \\
\hline \multicolumn{4}{|l|}{ M stage } \\
\hline M1 vs. M0 & -0.812 & 0.292 & 0.591 \\
\hline Gross type & & 1.090 & 0.341 \\
\hline Ulceroinfiltrative vs. Polypoid & 3.243 & 2.052 & 0.156 \\
\hline Ulcerofungating vs. Polypoid & 2.173 & 0.925 & 0.339 \\
\hline \multirow{2}{*}{ Variable } & \multicolumn{3}{|c|}{ Multiple linear regression } \\
\hline & Estimate & F-statistic & $P$-value \\
\hline $\mathrm{BMI}$ & 0.358 & 2.901 & 0.094 \\
\hline Maximum size of lesion & 0.091 & 11.473 & 0.001 \\
\hline $\mathrm{HbA} 1 \mathrm{c}$ & 0.282 & 0.790 & 0.378 \\
\hline \multicolumn{4}{|l|}{ T stage } \\
\hline T3, T4 vs. Tis, T1, T2 & 1.779 & 0.599 & 0.442 \\
\hline
\end{tabular}

DM, diabetes mellitus; HbA1c, glycated hemoglobin; Mucinous ca., mucinous carcinoma; Adenoca., adenocarcinoma.

out DM. There was no significant difference between tumor $\mathrm{SUV}_{\max }$ in patients with and without DM $(10.1 \pm 5.9$ vs. $8.7 \pm 5.6$ $[P=0.44])$. When Gorenberge et al. ${ }^{11}$ compared $\mathrm{SUV}_{\max }$ between 40 lung cancer patients with DM and 145 lung cancer patients without DM, no significant difference in $\mathrm{SUV}_{\text {max }}$ was shown between patients with and without DM (5.86 \pm 3.97 vs. $6.47 \pm 5.48)$. Collectively, these results indicate that DM has 
an insignificant effect on the $\mathrm{SUV}_{\max }$ values of PET-CT scans.

In the current study we used HbAlc levels to compare $\mathrm{SUV}_{\text {max }}$ according to the degree of blood glucose controlled in patients with DM. When patients with well-controlled glucose levels (HbAlc $<8 \%)$ and poorly controlled glucose levels (HbAlc $\geq 8 \%$ ) were compared, no significant difference was found in $\mathrm{SUV}_{\text {max }}$ between the groups. Gorenberge et al. ${ }^{11}$ reported no difference in $S U V_{\text {max }}$ in patients with DM when comparing groups with different fasting blood sugar levels ( $\geq 126 \mathrm{mg} / \mathrm{dL}$ vs. $<126 \mathrm{mg} / \mathrm{dL}$ ). Moreover, a study of 219 subjects with cervical cancer compared 16 patients with DM and hyperglycemia, 12 patients with DM and normal glucose levels, and 191 patients without DM. $\mathrm{SUV}_{\max }$ values were $12.83 \pm 11.47,13.86 \pm 7.90$, and $13.34 \pm 7.78$ in each group, respectively, showing no difference. ${ }^{12}$ These results imply that chronic hyperglycemia also has an insignificant influence on the $\mathrm{SUV}_{\max }$ values of PET-CT scans.

There are several reasons why the presence of DM in patients with colorectal cancer would not result in differences in tumor $\mathrm{SUV}_{\max }$ values, one being elevated tumor FDG uptake.

First, as part of the mechanism of increased glucose metabolism in cancer cells, a number of glucose transporter (GLUT1-GLUT7) genes are involved in the uptake of glucose to the plasma membrane. Of these GLUTs, an increase in the expression of GLUT1 and GLUT3 within tumors has been previously reported. ${ }^{13,14}$ Because increased expression of GLUTs in tumors is sufficient to offset tumor uptake of FDG caused by increased glucose levels through competition, no differences were found in $\mathrm{SUV}_{\text {max }}$ values according to DM and blood glucose regulation.

Second, invasive cancer associated with ulceration is characterized by molecular biological instability and a large number of inflammatory cells. ${ }^{15}$ Most of the subjects in our study had ulcerative-type lesions of colorectal cancer (88.8\% in patients with DM, $87.7 \%$ in patients without DM). The lack of differences in $\mathrm{SUV}_{\text {max }}$ between these groups may be related to increased FDG uptake attributable to the large number of inflammatory cells that had a greater effect than the competitive inhibition of FDG uptake within tumors with elevated glucose levels.

The results of previous studies have suggested that OHAs can influence intestinal absorption of FDG in patients with DM. In particular, metformin has been shown to stimulate adenosine monophosphate-activated protein kinase in cells and to increase FDG uptake by mobilizing GLUT4 from the microsomal membrane to the plasma membrane. ${ }^{16,17}$ Gontier et al. ${ }^{18}$ performed PET scanning in 32 patients with DM receiving OHA therapy with metformin and insulin, 23 undergoing OHA therapy without metformin and insulin, and 95 patients without DM. As a result, a significant increase was observed in intestinal FDG uptake in patients undergoing OHA therapy with metformin and insulin as compared to the other groups. Moreover, a comparative study on 77 patients with DM and 77 healthy individuals reported that a significant increase in intestinal FDG uptake was observed in patients with DM receiving metformin. ${ }^{19}$ In the current study, no differences in $\mathrm{SUV}_{\text {max }}$ were found among patients receiving OHA (71.2\%), insulin (12.5\%), combined insulinOHA therapy (3.8\%), or follow-up (12.5\%). However, different OHAs including metformin, sulfonylureas, meglitinides, and alpha-glucosidase were administered to patients, and only three patients underwent combined therapy with insulin. For these reasons, large-scale studies are needed to further investigate the effects of OHAs on $\mathrm{SUV}_{\text {max }}$.

The current study displayed a few limitations. First, blood glucose levels and PET scan periods may have varied in subjects due to the retrospective nature of the study. However, the impact of different blood collection times is thought to be minimal in the comparison of $\mathrm{SUV}_{\text {max }}$ by DM, as PET-CT scans were performed in patients during their hospital stay and at a glucose level $<180 \mathrm{mg} / \mathrm{dL}$. Second, there was no difference in $\mathrm{SUV}_{\max }$ according to the types of OHAs used by patients in this study. However, the scope of this study was limited to analyze only the results based on the presence of DM. Third, a PET scan is usually done about an hour after the injection of ${ }^{18}[\mathrm{~F}]-\mathrm{FDG}$. The difference in FDG uptake may have been partially caused by inconsistent periods between PET-CT scans. This may not have been problematic, however, considering the outcomes of recent studies that have demonstrated that the SUV does not reach maximum until 130-500 min after injection of ${ }^{18}[\mathrm{~F}]-F D G$ in animal tests ${ }^{20}$ and that ${ }^{18}[\mathrm{~F}]-\mathrm{FDG}$ uptake is known to persist for $2-3$ hours. $^{21,22}$

In conclusion, there was no difference in $\mathrm{SUV}_{\max }$ values dependent on the presence of DM when performing ${ }^{18}[\mathrm{~F}]$ FDG PET-CT scans in patients with colorectal cancer. Additionally, no association was found between glucose levels and $\mathrm{SUV}_{\text {max }}$. Therefore, the results of the current study demonstrated that DM did not influence FDG uptake values in colorectal cancer patients.

\section{REFERENCES}

1. Jung KW, Park S, Kong HJ, et al. Cancer statistics in Korea: incidence, mortality, survival, and prevalence in 2009. Cancer Res 
Treat 2012;44:11-24.

2. Park SK, Park MK, Suk JH, et al. Cause-of-death trends for diabetes mellitus over 10 years. Korean Diabetes J 2009;33:65-72.

3. Yi BD, Bae YP, Kim BG, et al. The association between type 2 diabetes mellitus and colorectal cancer. Endocrinol Metab 2011;26:126-132.

4. Larsson SC, Orsini N, Wolk A. Diabetes mellitus and risk of colorectal cancer: a meta-analysis. J Natl Cancer Inst 2005;97:1679-1687.

5. Endo K, Oriuchi N, Higuchi T, et al. PET and PET/CT using ${ }^{18} \mathrm{~F}-$ FDG in the diagnosis and management of cancer patients. Int J Clin Oncol 2006;11:286-296.

6. Lee JC, Hartnett GF, Hughes BG, Ravi Kumar AS. The segmental distribution and clinical significance of colorectal fluorodeoxyglucose uptake incidentally detected on PET-CT. Nucl Med Commun 2009;30:333-337.

7. Lindholm P, Minn H, Leskinen-Kallio S, Bergman J, Ruotsalainen U, Joensuu H. Influence of the blood glucose concentration on FDG uptake in cancer--a PET study. J Nucl Med 1993;34:1-6.

8. Diederichs CG, Staib L, Glatting G, Beger HG, Reske SN. FDG PET: elevated plasma glucose reduces both uptake and detection rate of pancreatic malignancies. J Nucl Med 1998;39:10301033.

9. Langen KJ, Braun U, Rota Kops E, et al. The influence of plasma glucose levels on fluorine-18-fluorodeoxyglucose uptake in bronchial carcinomas. J Nucl Med 1993;34:355-359.

10. Haley M, Konski A, Li T, et al. Influence of diabetes on the interpretation of PET scans in patients with esophageal cancer. Gastrointest Cancer Res 2009;3:149-152.

11. Gorenberg M, Hallett WA, O’Doherty MJ. Does diabetes affect $\left[{ }^{18} \mathrm{~F}\right]$ FDG standardised uptake values in lung cancer? Eur J Nucl Med Mol Imaging 2002;29:1324-1327.

12. Chang YC, Yen TC, Ng KK, et al. Does diabetes mellitus influence the efficacy of FDG-PET in the diagnosis of cervical can- cer? Eur J Nucl Med Mol Imaging 2005;32:647-652.

13. Brown RS, Leung JY, Kison PV, Zasadny KR, Flint A, Wahl RL. Glucose transporters and FDG uptake in untreated primary human non-small cell lung cancer. J Nucl Med 1999;40:556-565.

14. Marom EM, Aloia TA, Moore MB, et al. Correlation of FDG-PET imaging with Glut-1 and Glut-3 expression in early-stage nonsmall cell lung cancer. Lung Cancer 2001;33:99-107.

15. Kim SY, Lee SY, Lim HK, et al. Relationship between positron emission tomography uptake and macroscopic findings of colorectal cancer. Intest Res 2012;10:168-175.

16. Zou MH, Kirkpatrick SS, Davis BJ, et al. Activation of the AMPactivated protein kinase by the anti-diabetic drug metformin in vivo. Role of mitochondrial reactive nitrogen species. J Biol Chem 2004;279:43940-43951.

17. Walker J, Jijon HB, Diaz H, Salehi P, Churchill T, Madsen KL. 5-aminoimidazole-4-carboxamide riboside (AICAR) enhances GLUT2-dependent jejunal glucose transport: a possible role for AMPK. Biochem J 2005;385:485-491.

18. Gontier E, Fourme E, Wartski M, et al. High and typical ${ }^{18}$ F-FDG bowel uptake in patients treated with metformin. Eur J Nucl Med Mol Imaging 2008;35:95-99.

19. Bybel B, Greenberg ID, Paterson J, Ducharme J, Leslie WD. Increased F-18 FDG intestinal uptake in diabetic patients on metformin: a matched case-control analysis. Clin Nucl Med 2011;36:452-456.

20. Zhuang H, Pourdehnad M, Lambright ES, et al. Dual time point ${ }^{18}$ F-FDG PET imaging for differentiating malignant from inflammatory processes. J Nucl Med 2001;42:1412-1417.

21. Lodge MA, Lucas JD, Marsden PK, Cronin BF, O'Doherty MJ, Smith MA. A PET study of ${ }^{18}$ FDG uptake in soft tissue masses. Eur J Nucl Med 1999;26:22-30.

22. Matthies A, Hickeson M, Cuchiara A, Alavi A. Dual time point ${ }^{18}$ F-FDG PET for the evaluation of pulmonary nodules. J Nucl Med 2002;43:871-875. 